\title{
Impact of a Longitudinal Lecture Series on Pre-dental Student Recruitment
}

\author{
Jonathan Shapiro ${ }^{1}$, Cameron Lee ${ }^{2}$, Sang E. Park ${ }^{3}$ \\ ${ }^{1}$ DMD candidate, Harvard School of Dental Medicine, USA \\ ${ }^{2}$ Resident, Department of Oral and Maxillofacial Surgery, Massachusetts General Hospital, USA \\ ${ }^{3}$ Associate Dean for Dental Education, Harvard School of Dental Medicine, USA \\ Correspondence: Sang E. Park, Harvard School of Dental Medicine, 188 Longwood Avenue, Boston, MA 02115, USA.
}

Received: December 15, 2016

Accepted: March 23, 2017 Online Published: March 26, 2017

doi:10.11114/jets.v5i5.2079

URL: https://doi.org/10.11114/jets.v5i5.2079

\begin{abstract}
The expanding number of dental schools has not resulted in a rise in dental school applications; therefore, there is a need to identify and retain pre-dental students in the applicant pool. One way to do this is to introduce an outreach program by dental schools. A limited number of studies have been done on the impact of outreach programs on dental school recruitment.

This study was done to examine the effectiveness of an outreach program initiated at the Harvard School of Dental Medicine (HSDM). Third- and fourth-year dental students provided 12 hours of lectures, two hours of case-based learning, and two hours of hands-on laboratory experience to pre-dental students over 12 weeks in a course called Introduction to Dentistry. The course was given in 2015 and 2016 and the participants were surveyed before and after the course to determine their interest in and knowledge of dentistry, and their attitude toward HSDM. After the course, pre-dental students had better understanding of the dental profession overall, were more comfortable conversing about dentistry, and were more likely to apply to HSDM in the future.

Dental outreach programs can maintain or increase interest in applicants who were previously interested in applying to dental school; however, admissions committees must carefully consider an applicant's entire academic and personal background. Participation in an outreach program is not an indication of an applicant's overall suitability for dentistry in general or for a particular dental school's program.
\end{abstract}

Keywords: predoctoral education, outreach program, admissions, undergraduate students

\section{Introduction}

According to reports from the American Dental Education Association, since 1997 a total of 13 new dental schools have opened in the US (American Dental Education Association, 2014). Reports from the same organization indicate that the number of dental school applicants has remained approximately the same over a similar timeframe resulting in an increased rate of enrollment of applicants (Garrison, McAllister, Anderson, \& Valachovic, 2013; American Dental Education Association, 2015a; American Dental Education Association, 2015b). As the educational landscape continues to expand, there will be increasing need at local and regional levels to identify and retain pre-dental students in the applicant pool.

Dental schools have incorporated various admissions strategies, and pipeline programs have to provide diverse applicants for dental school admissions. Holistic admissions processes have been linked to positive outcomes in the underrepresented minority (URM) student enrollment (Nalliah, Park, Timothe, De Leon, Howell, \& Allareddy, 2014; Price \& Grant-Mills, 2010). A holistic application review entails evaluation of candidates not only for standard criteria such as GPA and DAT scores, but also for variables that contribute to improving student diversity. Admissions committees conduct comprehensive reviews of an applicant, including community service experience, dental shadowing, letters of recommendation and other personal attributes, such as overcoming adversities and life experience.

Enrichment programs for pre-dental students can be an important tool in that they expose applicants to mentorship opportunities and further strengthen their motivation to pursue a career in dentistry. One method by which dental schools are able to showcase their programs and facilities is through outreach programs. Such programs geared towards prospective students may provide a cost-effective method of generating both exposure and interest among pre-dental 
students in the region. While many of these types of programs are known to exist, there have been few reported studies in the literature quantitatively examining their impact on recruitment (Markel, Woolfolk, \& Inglehart, 2008; McClain M, Jones, McClain C, \& Curd, 2013; Johnson, Woolfolk, May, \& Inglehart, 2013; Suen, Lai, Bridges, \& Chu, 2014). To date, only a few dental schools have taken a quantitative approach to examining recruitment patterns within their outreach programs (Hawley, Dye, \& Ditmyer, 2009; Fenesy \& DeCastro, 2008). Of these, only one provides longitudinal exposure over two days.

The purpose of this study was to highlight an outreach program recently initiated at the Harvard School of Dental Medicine and report outcomes on two cohorts. The program, entitled Introduction to Dentistry, is a longitudinal lecture and laboratory series that aims to provide pre-dental students with sustained exposure to the school and profession. We hypothesized that the course would improve self-reported interest and knowledge in the dental profession, as well as attitudes toward the profession.

\section{Methods}

The study was reviewed and approved by the Institutional Review Board (IRB) at Harvard Medical School and the Harvard School of Dental Medicine.

This was a prospective cohort study of all enrolled pre-dental students in the Introduction to Dentistry course at the Harvard School of Dental Medicine (HSDM) in the spring of 2015 and 2016. The course consisted of sixteen hours of didactic and laboratory instruction delivered over a twelve-week period by current $3 \mathrm{rd}$ and 4 th year dental students. The curriculum included twelve hours of lecture, two hours of case-based learning, and two hours of hands-on laboratory experience (Figure 1). The course was taught entirely by students; the faculty's role was limited to confirming that information used in the course was accurate.

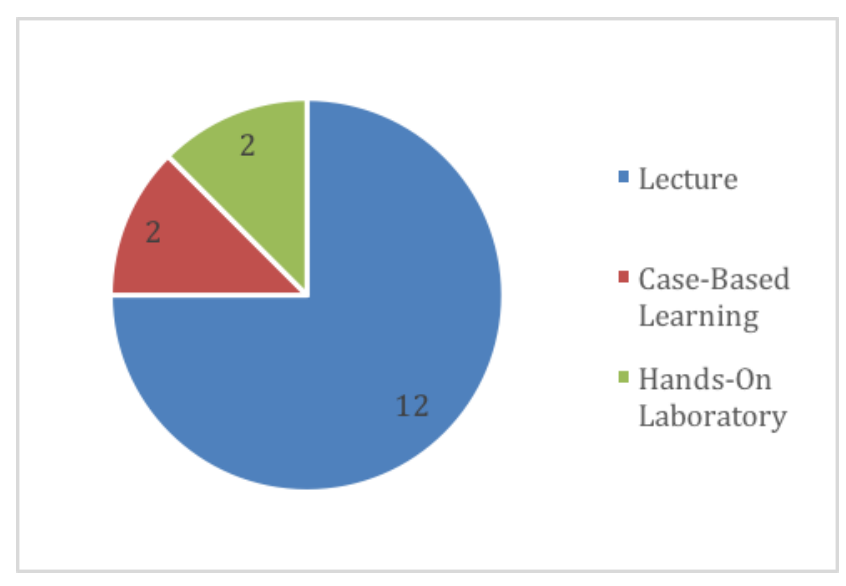

Figure 1. Course Hours Breakdown Lecture comprised 12 hours of the course, while case based learning and hands-on laboratory activities each comprised two hours

Pre-and post-course surveys were administered to all participants (Figure 2). The survey was comprised of three sections. In the first section, basic demographic information including age, gender, education level, and area of study was collected. In the second section, students' self-reported interest in, and knowledge of, the dental profession, as well as attitudes towards HSDM, were assessed using a Likert scale from 1 (strongly agree) to 5 (strongly disagree). The third section was only administered upon course completion, and included questions regarding student satisfaction and difficulty of material. 
1) I feel that I have a good grasp of my professional goals with respect to the dental profession
Strongly agree
Agree $\square$ Neutral
Disagree
Strongly disagree

2) I am currently interested in pursuing a career in dentistry
Strongly agree
Agree $\square$ Neutral
Disagree
Strongly disagree

3) I feel comfortable having a conversation about dental related topics (e.g. interview setting)

$\square$ Strongly agree $\quad \square$ Agree $\square$ Neutral $\square$ Disagree $\square$ Strongly disagree

4) I feel that I have a solid understanding of the different fields in the dental profession
Strongly agree
Agree $\square$ Neutral
Disagree
Strongly disagree

5) I have a favorable perception of HSDM as an educational program
Strongly agree
Agree $\square$ Neutral
Disagree
Strongly disagree
6) I am likely to apply to HSDM in the future
$\square$ Strongly agree $\square$ Agree $\square$ Neutral
Disagree
Strongly disagree

Figure 2. Survey of student knowledge of dentistry and attitudes towards HSDM

Statistical analysis was performed using Graphpad 6.0 (La Jolla, CA). Student's t-test was used to compare pre and post survey results with an alpha of $<0.05$ considered significant. IRB approval and written consent from all participants were obtained prior to the study.

\section{Results}

A total of 26 pre-dental students were enrolled in the study and 24 (6 males, mean age 21.0 years) completed the entry and exit surveys. Of the 24 students, 20 were current undergraduate students, while 4 had previously attained an undergraduate degree. There were 13 universities represented. Twenty-one of the students lived in Massachusetts and three commuted from nearby states (New York and Connecticut). The majority of students were in their junior year of undergraduate study or later, and indicated that they would be applying to dental schools in the next 2 years. See Table 1 for complete demographic information.

Table 1. Demographic information

\begin{tabular}{ll}
\hline Demographic & Value \\
\hline Sex & 20 \\
Female & 6 \\
Male & $21 \pm 2.3$ years old \\
Age & 24 \\
Residence & 1 \\
Massachusetts & 1 \\
Connecticut & \\
New York & 5 \\
Year in School & 3 \\
First Year & 9 \\
Second Year & 2 \\
Third Year & 2 \\
Fourth Year & 3 \\
Fifth Year & 1 \\
Graduate & \\
Other & 14 \\
Major & 2 \\
Biology & 1 \\
Neuroscience & 2 \\
Bioengineering & 1 \\
Biochemistry & 3 \\
Immunology & 2 \\
Chemistry & Other
\end{tabular}

Baseline surveys indicated that enrolled students had a good grasp of their professional goals with respect to the dental profession (mean $=1.81 \pm 0.94$; agree) and were highly motivated to pursue a career in dentistry (mean $=1.23 \pm 0.51$; strongly agree). However, responses regarding degree of comfort conversing about dental related topics $($ mean $=2.35 \pm 0.94)$ as well as knowledge about the different specialties (mean $=2.58 \pm 1.06)$ were notably lower. Attitudes towards HSDM were overall favorable (mean $= \pm 1.73 \pm 0.60$; agree) and students reported that they were likely to apply in the future (mean $=2.12 \pm 0.82$; agree). 
Compared to baseline surveys, students reported a better understanding of the dental profession overall $(\mathrm{p}<0.05)$, increased comfort having a conversation about dentistry $(\mathrm{p}<0.001)$, and were more likely to apply to HSDM in the future ( $p$ < 0.05) after completion of the course. No significant difference was found with respect to interest in pursuing a career in dentistry, development of professional career goals, and perception of HSDM as an educational program. Additionally, questions regarding quality and calibration of course material administered only upon completion of the course were overall favorable.

A total of 22 current dental students participated in the course as teachers in some capacity and reported favorable feedback regarding involvement.

\section{Discussion}

Outreach programs provide dental schools with the opportunity to serve the community while benefiting their students from an educational standpoint. The results of this study may have implications for pre-dental student recruitment and the creation of teaching opportunities for dental students. A number of states are known to have deficient numbers of applicants to supply the need for the dental workforce at local and regional levels (Mentasti \& Thibodeau, 2008). It is necessary for dental schools to consider initiatives and programs to broaden the amount of prospective applicants interested in the dental profession.

It is also critical that dental schools are able to predict the future academic performance and clinical competency of students in the dental curriculum to optimize the admissions and graduation process (Park, Susarla, \& Massey, 2006). Applicants must be weighed to assess their suitability for dentistry, and also for the specific dental school program, as overall performance in dental school is confounded by various factors in addition to the individual's motivation and these additional factors must be considered in selecting the candidates for admissions (Park, Da Silva, Barnes, Susarla, \& Howell, 2010). Dental school admissions committees should continue to review a full spectrum of variables and ensure an applicant's true interest and motivation to pursue a career in dentistry.

Several pipeline programs have become available to increase the number of underrepresented minority (URM) applicants in the health professional schools (Markel, Woolfolk, et al., 2008; Gravely, McCann, Brooks, Harman, \& Schneiderman, 2004). The enrichment programs provide different resources, such as academic skills for science classes and the DAT to improve students' understanding of the dental profession as well as to better prepare them for successful dental school admissions. In addition, the program at HSDM included peer mentorship opportunities where the dental students were paired with pre-dental students.

It is presumed that if a student sought out a pre-dental outreach experience, it could be indicative of the student's commitment to joining the dental profession. It may reflect a student's actual interest and motivation level in dentistry. In addition, the experience itself may expose the student to the materials, techniques, and thought processes involved in dentistry. In order to substantiate its use as a predictive agent, it should be determined if there is a correlation between assisting experience and performance in dental school. Having experiences that lend background knowledge related to the materials and techniques in dentistry could accelerate a student's acquisition of dental knowledge leading to better performance in dental school (Park, Da Silva, et al., 2010).

There may also be other intangible benefits, such as cost savings. A study on nonacademic characteristics of dental school applicants indicated that few participate in formal dental programs other than shadowing in 2 offices (Mentasti \& Thibodeau, 2006). Many prospective applicants do not know what dental school is like and do not have exposure to the diversity of careers within dentistry. Pre-dental programs can help shape the interest of prospective applicants for the dental profession (Fenesy \& DeCastro, 2008).

The results of this study may have implications for pre-dental student recruitment and the creation of teaching opportunities for dental students. Additional studies are ongoing to measure further impact in dental admissions to evaluate mentoring program efficacy and measure its effectiveness. Future directions for the pilot program include introducing preparatory materials and opportunities for applicants with disadvantaged backgrounds.

\section{Conclusion}

Dental schools are experiencing a plateau in the number of applicants, despite an increase in the number of dental schools. Outreach programs are one way to increase the applicant pool and maintain interest in the profession of dentistry. The outreach program at HSDM produced a self-reported increase in participant understanding of the dental profession and comfort in discussing dental topics. Although admissions committees must still consider the applicant as a whole, beyond their academic and technical skills, outreach programs that produce similar results to the one at HSDM could also produce an applicant pool that is more aware of the general demands of dental school and the general atmosphere of the particular school through its outreach program. 


\section{References}

American Dental Education Association. (2014). ADEA Deans Briefing Book 2014-2015. Retrieved from www.adea.org/deansbriefing

American Dental Education Association. (2015a). Applicant/First-Year Enrollee Ratio, 1980-2015. Retrieved from www.adea.org/publications-and-data/data-analysis-and-research/applicants-enrollees-and-graduates.aspx

American Dental Education Association. (2015b). Percent of Applicants Enrolled in Dental School, 2000-2015. Retrieved

from www.adea.org/publications-and-data/data-analysis-and-research/applicants-enrollees-and-graduates.aspx

Fenesy, K. E., \& DeCastro, J. E. (2008). A predental school experience to expose potential applicants to dental school and the dental profession. Journal of Dental Education, 72, 593.

Garrison, G. E., McAllister, D. E., Anderson, E. L., \& Valachovic, R. W. (2013). U.S. dental school applicants and enrollees, 2011 and 2012 entering classes. Journal of Dental Education, 77, 1677.

Gravely, T., McCann, A., Brooks, E., Harman, W., \& Schneiderman, E. (2004). Enrichment and recruitment programs at dental schools: impact on enrollment of underrepresented minority students. Journal of Dental Education, 68(5), 542-552.

Hawley, N., Dye, J., \& Ditmyer, M. (2009). Knowledge, attitudes, and perceptions of participants and instructors taking part in a dental school simulation course for potential dental students. Journal of Dental Education, 73, 483.

Johnson, K. P., Woolfolk, M., May, K. B., \& Inglehart, M. R. (2013). Effect of an enrichment program on DAT scores of potential dental students from disadvantaged backgrounds. Journal of Dental Education, 77, 1063.

Markel, G., Woolfolk, M., \& Inglehart, M. R. (2008). Feeding the pipeline: academic skills training for predental students. Journal of Dental Education, 72, 653.

McClain, M. A., Jones, F. R., McClain, C. R., \& Curd, F. M. (2013). Increasing dental student diversity through the UNLV Dental Prospects Program. Journal of Dental Education, 77, 548.

Mentasti, L. E., \& Thibodeau, E. A. (2006). Nonacademic characteristics of dental school applicants. Journal of Dental Education, 70, 1043-1050.

Mentasti, L. E., \& Thibodeau, E. A. (2008). Dental school applicants by state compared to population and dentist workforce distribution. Journal of Dental Education, 72(11), 1290-1295.

Nalliah, R. P., Park, S. E., Timothe, P., De Leon, R., Howell, T. H., \& Allareddy, V. (2014). How can we recruit under-represented minorities into the dental profession in Massachusetts? Journal of the Massachusetts Dental Society, 63(1), 18-20.

Park, S. E., Susarla, S. M., \& Massey, W. L. (2006). Do admissions data and NBDE Part I scores predict clinical performance among dental students? Journal of Dental Education, 70(5), 518-524.

Park, S. E., Da Silva, J. D., Barnes, J. L., Susarla, S. M., \& Howell, T. H. (2010). Predicting dental school performance based on prior dental experience and exposure. European Journal of Dental Education, 14(1), 1-6. https://doi.org/10.1111/j.1600-0579.2009.00611.x

Price, S. S., \& Grant-Mills, D. (2010). Effective admissions practices to achieve greater student diversity in dental schools. Journal of Dental Education, 74(10 suppl), S87-97.

Suen, R. P., Lai, S. M., Bridges, S., \& Chu, C. H. (2014). Students' satisfaction with a dental summer programme and importance of influencing factors for choosing dentistry as their career. European Journal of Dental Education, 18, 104. https://doi.org/10.1111/eje.12063

\section{Copyrights}

Copyright for this article is retained by the author(s), with first publication rights granted to the journal.

This is an open-access article distributed under the terms and conditions of the Creative Commons Attribution license which permits unrestricted use, distribution, and reproduction in any medium, provided the original work is properly cited. 